\title{
O tom valorativo como estratégia argumentativa no gênero comentário on-line
}

\author{
Alixandra Guedes Rodrigues de Medeiros e Oliveira \\ Doutoranda em Linguística pela Universidade Federal da Paraíba (UFPB), Brasil. \\ Bolsista CAPES, proc. 88882.182506/2018-01. \\ alixandragm@gmail.com

\section{Pedro Farias Francelino} \\ Professor Doutor da Universidade Federal da Paraíba (UFPB), Brasil. \\ pedrofrancelino@yahoo.com.br
}

Resumo: Pensando a argumentação como uma tomada de posição em relação a outra posição que se realiza no contexto dialógico, o presente trabalho objetiva analisar como o tom valorativo contribui para a construção da argumentação nos comentários on-line que têm por motivação a tira em quadrinhos "Chegando a Deus", produzida pelo designer e ilustrador Carlos Ruas. Para tanto, buscamos respaldo na Análise Dialógica do Discurso (BAKHTIN, 2010, 2011, 2016; VOLOCHÍNOV, 2013) e nos estudos realizados acerca da Argumentação (FIORIN, 2017). Do ponto de vista do resultado da análise, constatamos que os sujeitos fazem uso da valoração como mecanismo de argumentação para problematizar a prática do dízimo em contextos eclesiásticos religiosos, utilizando de artifícios argumentativos, como a comparação e a autoridade para tal, postura imanente ao jogo argumentativo.

Palavras-chave: Valoração. Argumentação. Tiras. Comentário on-line.

Abstract: Thinking the argument as a positioning in relation to the other position that takes place in the dialogical context, the present work aims analyze how the valorative tone contributes to the argument construction in the online comments motivated by comic strip "Chegando a Deus", produced by the designer and illustrator Carlos Ruas. Therefore, we seek support in Dialogical Discourse Analysis (BAKHTIN, 2010, 2011, 2016, VOLOCHÍNOV, 2013) and studies on Argumentation (FIORIN, 2017). From the analysis result point of view, we find that the subjects make use of valuation as a argumentation mechanism to problematize the tithing practice in religious ecclesiastical contexts, using argumentative artifices, such as comparison and authority for such, immanent posture argumentative.

Keywords: Valuation. Argumentation. Comic strips. Online comment. 
Introdução

O sujeito, em suas práticas sociais de linguagem, manifesta pontos de vista diferentes e divergentes em sua relação com os outros e com o mundo. A língua e o texto assumem, nesse sentido, o lugar da materialidade discursiva em que as palavras revelam-se carregadas de sentidos veiculados por variados conteúdos ideológicos. Por conseguinte, a tensão dialética é uma das principais características do signo linguístico e nele habitam, concomitantemente, valores que produzem sentidos diversos, mesmo antagônicos, por refletirem de modo polêmico o objeto do discurso e o sujeito e seu horizonte socioideológico.

É, pois, nesse processo interativo que se estabelecem as relações dialógicas e por meio delas podemos perceber os diversos tons emotivovolitivos nos enunciados. Nesse jogo de dizeres, o discurso se constitui sempre sob(re) outro discurso, de forma que todos os discursos são argumentativos, já que todos eles - em maior ou menor grau - fazem parte de uma polêmica, refutando, apoiando, contestando, sustentando um dado ponto de vista, pois são uma atitude responsiva a outros enunciados proferidos, figurando como uma espécie de faísca que produz concordâncias e discordâncias no âmbito do dizer.

Embasado num viés discursivo, este trabalho realiza uma análise dialógico-discursiva da valoração como estratégia argumentativa utilizada no gênero comentário on-line, gerado a partir da tira em quadrinhos "Chegando a Deus", produzida pelo designer e ilustrador Carlos Ruas, publicada na página de Facebook "Um Sábado Qualquer", no dia 6 de setembro de 2017, que versa sobre a cobrança de dízimos por parte de igrejas cristãs.

A hipótese levantada é a de que os enunciados produzidos em resposta à tira publicada caracterizam-se como produções argumentativas na medida em que os internautas se utilizam de tons valorativos para condenar a prática do dízimo. Para tanto, a análise foi desenvolvida a partir de comentários e réplicas produzidos sobre a tira motivadora. Os comentários foram selecionados a partir da consideração de dois critérios: apresentar mais de cinco réplicas e apontar posicionamentos distintos.

Nosso trabalho está organizado em quatro seções: na primeira, abordamos uma discussão teórica sobre o conceito de tom valorativo a partir da perspectiva dialógica (BAKHTIN, 2010, 2011, 2016); na segunda, explanamos sobre a argumentatividade e $(\mathrm{m})$ suas diferentes estratégias (FIORIN, 2017); na 
terceira, discorremos sobre o gênero comentário on-line e, por fim, apresentamos a análise empreendida relativa à presença da valoração enquanto elemento argumentativo nos enunciados verbo-visuais, sobre a referida tira, presentes na rede social Facebook.

\section{Sobre o conceito de valoração}

A linguagem, sob a perspectiva da Análise Dialógica do Discurso (doravante $A D D$ ), requer o entendimento da língua como resultado não acabado da vida verbal em contextos específicos de comunicação e de interação. Compreendendo que "a língua passa a integrar a vida mediante enunciados concretos (que a realizam), é igualmente por meio de enunciados concretos que a vida entra na língua" (BAKHTIN, 2011, p. 265).

No curso da interação dialógica, o enunciado apresenta como partes integrantes um projeto (a intenção do dizer), um autor (o sujeito) e a execução (a realização por parte do sujeito de sua própria intenção). Por possuir natureza ativamente responsiva, toda compreensão é desejante de resposta e é essa condição que constitui cada enunciado como um elo na corrente complexamente organizada de outros enunciados (BAKHTIN, 2011, p. 272).

Há em Bakhtin (2011) uma explanação sobre o vivenciamento ativo do eu que sintetiza bem a concepção de valoração desse autor, servindo de referência à reflexão neste tópico:

Tendo da minha vivência uma lembrança axiologicamente ativa não da parte do seu conteúdo presente, tomado isoladamente, mas da parte do seu sentido antedado e do objeto, isto é, da parte do que assimilou o surgimento dele em mim, e assim torno a renovar o antedado de cada vivência minha, reúno todas as minhas vivências, reúno a mim todo não no passado, mas no futuro eternamente vindouro. (BAKHTIN, 2011, p. 114-115).

É possível perceber nas palavras do autor que o sentido de valoração é explicado a partir da própria noção de dialogismo. É possível a compreensão de que as axiologias estão intimamente ligadas ao histórico e ao seu devir. Em outras palavras, o vivenciamento ativo do eu é sempre uma atividade axiológica; valorar significa, portanto, dar o seu "aroma" às formas de interação verbal, "uma vez que não se trata do valor da vida para mim, mas do meu próprio valor para mim mesmo [...], eu suponho esse valor no futuro eivado de sentidos." (BAKHTIN, 2011, p. 112). 
Nessa perspectiva, o vivenciamento torna-se lembrança axiológica quando se refere ao caráter dialógico da linguagem. A escolha do substantivo lembrança pelo autor cumpre o papel de afirmar que há "rastros" de sentidos atravessando as experiências de linguagens dos sujeitos sociais. Torna-se relevante destacar, a partir dessas considerações, duas assertivas: a lembrança é uma forma de axiologia e a axiologia é ideológica.

Na primeira, é preciso reconhecer que as valorações são vinculadas ao tempo e ao espaço, ou seja, ao cronotopo, de modo que os sujeitos estão sempre implicados nas lembranças axiológicas/valorativas e elas mobilizam tons/apreciações diante dos eventos de interação social. No que tange à segunda assertiva - a axiologia é ideológica -, as valorações possuem uma filiação ideológica historicamente situada e editada pelas pressões sociais a que tais ideologias se relacionam. Assim, o enunciado sempre veicula uma ideologia e esta, por sua vez, sempre será social e histórica e, por isso, não pode ser resumida à sua face empírica nem tampouco fechada no mundo individual do sujeito (FARACO, 2009).

Sob a perspectiva de Bakhtin (2016), toda atividade de linguagem, a exemplo da manifestação verbal socialmente significativa, é determinada por tons axiológicos e "cada dia tem sua conjuntura socioideológica, semântica, seu vocabulário, seu sistema de acento, seus lemas, seu desaforo e seu elogio" (BAKHTIN, 2016, p. 66). A relação do sujeito com o mundo que o cerca ocorre de maneira oblíqua, tendo em vista que as palavras adentram as camadas dos discursos sociais que recobrem as coisas. Desse modo, "nossa relação com o mundo é sempre atravessada por valores” (FARACO, 2009, p. 49) e esses tons valorativos acabam por ser utilizados como força argumentativa frente às interações dialógicas vivenciadas.

\section{A argumentação}

A máxima de que a língua apresenta como característica intrínseca a argumentação é recorrente no âmbito dos estudos linguísticos, constituindose como o estudo das orientações semânticas dos enunciados e dos encadeamentos que as expressam, afastando-se da noção de discursivização postulada pela tradição retórica.

A argumentação como aspecto constitutivo da linguagem apresenta aspectos interiores e exteriores. Interiormente, é a organização das unidades 
discursivas transfrásticas, isto é, os operadores argumentativos, os elementos responsáveis pela argumentação nos discursos. Exteriormente, é o modo de funcionamento do discurso, ou seja, o seu caráter dialógico que assume o papel de orientador do discurso, no sentido de obter conclusões, resolver impasses. (FIORIN, 2017, p. 17).

À argumentação discursiva subjaz uma ideologia, não importando qual seja, pois até a neutralidade presente no discurso contém sua ideologia. Independentemente da origem do objeto do discurso de um sujeito, este (o objeto) não assume a posição de objeto de discurso pela primeira vez em um dado enunciado, tampouco o sujeito enunciador é o primeiro a falar sobre o objeto. "O objeto, por assim dizer, está sempre ressalvado, contestado, elucidado e avaliado de diferentes modos; nele se cruzam, convergem e divergem diferentes pontos de vista, visões de mundo, correntes." (BAKHTIN, 2011, p. 300).

Dentre as diversas formas de contestação e divergência apresentadas no ato interativo dialógico, os argumentos constituem estratégias como a inferência, a dedução, a indução, a analogia, o exemplo, a ilustração, a implicação, entre outros. Todos esses mecanismos discursivos são ativados pelo sujeito no momento da interação discursiva, dependendo do cronotopo no qual ele se encontra e do objeto do discurso em questão, reforçando a tese de que todos os discursos são argumentativos, visto que "a argumentação é uma questão de linguagem." (FIORIN, 2017, p. 78).

O processo argumentativo, para Pistori e Banks-Leite (2010, p. 132),

[...] surge não apenas em situações em que há controvérsias explícitas, em que a regra é a assunção de posições opostas, mas que é no discurso, por meio dos elementos da língua, que se constroem posicionamentos diante da realidade inclusive em termos de maior ou menor adesão do locutor a cada um deles; tais posicionamentos são argumentativos e visam a um auditório social determinado.

Assim, o sujeito está constantemente construindo discursos que explicam, ordenam, classificam o mundo à sua volta e o faz a partir de relações e dependências entre as diversas esferas ideológicas. Essa atitude resulta na formação de inúmeros "efeitos de sentido persuasivos, presentes no modo de produção, circulação e recepção desses discursos" (PISTORI, 2014, p. 150), de forma que o sentido só pode ser apreendido/depreendido quando inserido em contexto e a compreensão daquele que ouve/lê é, 
portanto, sempre ativa, sem se afastar da valoração em curso, seja no ato de responder, seja na própria compreensão.

\section{O gênero comentário on-line}

A partir da vivência social e da diversidade de posições avaliativas, surge "a riqueza e a diversidade dos gêneros" (BAKHTIN, 2011, p. 262), já que são "inesgotáveis as possibilidades da multiformalidade da atividade humana" (BAKHTIN, 2011, p. 262). Além disso, cada campo da comunicação discursiva dá origem e diferencia a variedade dos gêneros de acordo com a complexidade de suas atividades.

O gênero comentário on-line surge na sociedade com o advento da internet, seguindo os passos do gênero comentário, surgido na esfera jornalística na década de 1960 (MELO, 2003). Por ser um gênero do ambiente virtual, sua linguagem é espontânea e individual, apresentando gírias, perguntas, interpelações, expressões valorativas/depreciativas, emoticons etc. Apresenta como uma de suas características principais a liberdade de expressão, que revela a espontaneidade da escrita e a subjetividade do internauta, demarcando a alteridade enunciativa, já que coloca o internauta diante de várias vozes que dialogam sobre um mesmo assunto. Em seu conteúdo temático, fazem-se presentes reflexões sobre fatos da atualidade, em especial aqueles divulgados na mídia televisiva.

Em sua estrutura composicional, destacam-se alguns aspectos, tais como: é um texto curto; a identificação do comentarista nem sempre ocorre; o gênero simula um diálogo face a face, por apresentar-se como uma conversa espontânea; possui vida efêmera, pois o comentarista opina sobre fato que está em curso na história social (ARAÚJO, 2017). Desse modo, o gênero comentário on-line configura-se como um reflexo da individualidade do falante por apresentar como traço fortemente marcado o estilo de cada um dos internautas e por encerrar em sua composição as mudanças históricas dos estilos de linguagem ocorridas nas últimas décadas e que são inseparáveis dos gêneros do discurso.

Os comentários on-line encontrados na página de Facebook “Um Sábado Qualquer" figuram como materializações dialógicas que refletem os acontecimentos de variados campos discursivos da sociedade - em especial, o discurso religioso - e que conduzem o sujeito-leitor-internauta a atitudes 
valorativo-responsivas sobre o conteúdo materializado no gênero tira em quadrinhos. Mesmo que o sujeito-comentarista seja anônimo, o teor argumentativo permeia a materialização discursiva, já que o sujeito assume seu ponto de vista face ao outro, enunciando seus tons valorativos e responsabilizando-se inteiramente por seu posicionamento, uma vez que este fica arquivado na rede social e é replicado por outros sujeitos-internautas.

Por ocorrer no ambiente virtual, esse gênero é de fácil acesso e sua materialidade está fixada na rede social, não podendo ser alterado. De acordo com Kozinets (2014), o gênero comentário on-line compõe um vasto acervo para pesquisas acadêmicas, visto que não requer autorização, por ser de domínio público, além de poder ser acessado em qualquer lugar e em qualquer tempo.

\section{A valoração como estratégia argumentativa}

As tirinhas de "Um Sábado Qualquer" são de autoria do designer carioca Carlos Ruas e buscam de forma irreverente e bem-humorada tratar de um dos assuntos mais polêmicos do mundo: a religião. A página está ativa desde 2009, conta com uma produção semanal de tirinhas, é atualizada diariamente e apresenta um alcance significativo, com um número de 2.855 .178 milhões de seguidores, sendo as tirinhas de “Um sábado Qualquer” as mais acessadas do País.

A personagem da tira em análise é Deus, sua primeira personagem autoral, criada em 2009. Segundo o autor, a personagem é inspirada no humano, apresentando características como o ciúme, a inveja, a preguiça e o consumismo. As demais personagens são criações de Deus: Adão, personagem que representa o homem atual e que vive atormentado por 900 anos de conflito em seu relacionamento com Eva, além de viver resistindo às tentações de Lilith e tentando lidar com a TPM da esposa; Caim, filho de Adão e Eva, desde pequeno apresenta características psicopatas, o que leva Deus a sentir-se fracassado.

Compõem a tira, ainda, Lucicraldo, ou Luci, governante do mundo infernal, constantemente insatisfeito por isso, já que se sente injustiçado por ser usado como desculpa para as maldades humanas; por ser ingênuo, é sempre vítima das brincadeiras de Deus e de Adão; Jesus Cristo, filho de Deus, revela-se pacífico e ingênuo, prefere ficar jogando videogame a se tornar um guerreiro, o que causa tristeza em seu pai, que apesar disso o ama 


\section{$\mathrm{EI} \sqcap \mathrm{dA}$}

Revista Eletrônica de Estudos Integrados em Discurso e Argumentação, Ilhéus, n. 17, jul./dez. 2018.

incondicionalmente; e os humanos que estão sempre pedindo ou se queixando a Deus. Vejamos:

Figura 1 - Tira em quadrinhos "Chegando a Deus", de Carlos Ruas

\section{CHEGANDO A DEUS}

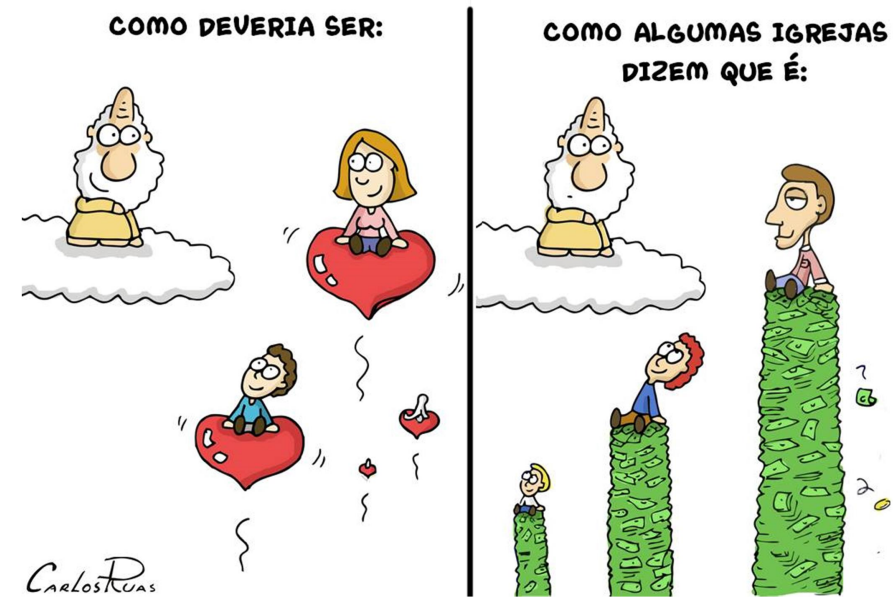

Fonte: www.facebook.com/umsabadoqualqueroficial. Publicado: 6 set.2017. Acesso: 5 out.2017

A tira que motivou os comentários on-line, foco desta análise, intitula-se “Chegando a Deus" e é composta por um único quadro, dividido em duas cenas. Na primeira cena, à esquerda, o personagem Deus está sentado em uma nuvem observando a chegada de humanos ao céu por meio de atos de amor e de bondade representados pelos corações que os conduzem. A expressão facial do personagem é de alegria e satisfação e é corroborada pelo enunciado "Como deveria ser".

Na segunda cena, à direita, vê-se o personagem na mesma posição, no entanto, sua expressão facial revela uma surpresa ao ver que a chegada dos humanos ao céu advém do pagamento do dízimo e doações, completando o sentido da decepção divina com o enunciado "Como algumas igrejas dizem que é".

Por ser o gênero tira em quadrinhos um texto verbo-visual, cujos elementos colaboram para a constituição de sentido (PUZZO, 2014, p. 174), a composição imagética e a escolha das cores expressam tons valorativos acerca do conteúdo temático: na primeira cena, a cor vermelha, que colore os corações que conduzem os humanos ao encontro de Deus, é representativa da condição humana, das dores e abnegações realizadas na busca pela graça 
do Pai Eterno, bem como remete ao resumo neotestamentário dos 10 mandamentos: amar a Deus e ao próximo.

Já na segunda cena, a cor verde é representativa da moeda americana, o dólar, símbolo do sistema capitalista que impera na atual sociedade e que tem como premissa o fato de que tudo tem um preço, inclusive a fé e o alcance do mundo celestial. Este enunciado configura-se como concreto ao encontrar apoio coral nas práticas disseminadas por algumas igrejas como a venda de indulgências e a cobrança de dízimos e doações que, por vezes, apresentam valor financeiro bastante elevado.

A tira suscitou diversos comentários na página. Metodologicamente, optamos por selecionar, dentre os comentários realizados sobre a tira "Chegando ao Deus", aquele que apresentasse mais de cinco réplicas. Dessa forma, selecionamos o segundo comentário postado na página do Facebook de “Um Sábado Qualquer”, realizado pelo sujeito " $\mathrm{CL} 1$ “, e as réplicas realizadas. Dividimos os turnos dialógicos em cinco blocos (denominados Figuras) com o objetivo de facilitar a leitura e a análise dos enunciados. Vejamos:

\section{Figura 2}

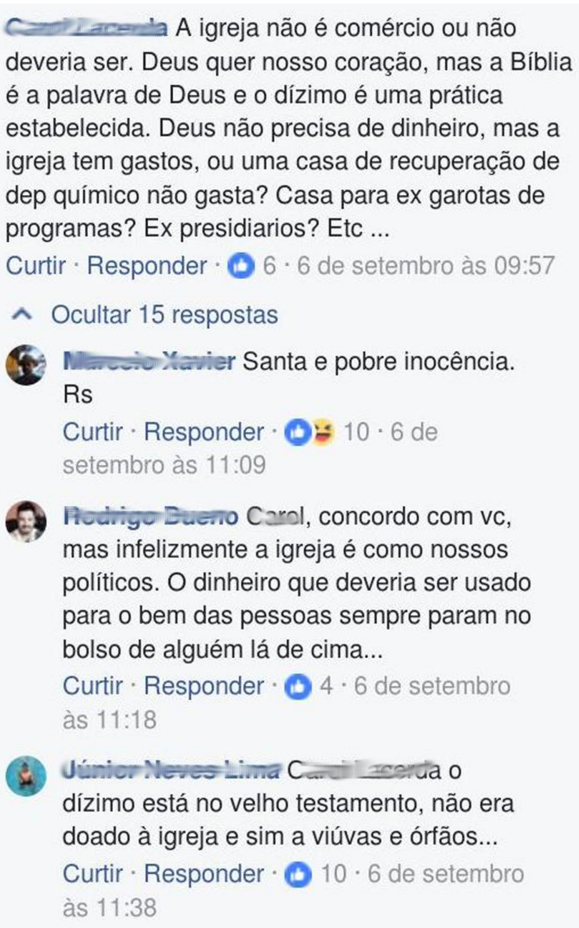

\section{Figura 3}

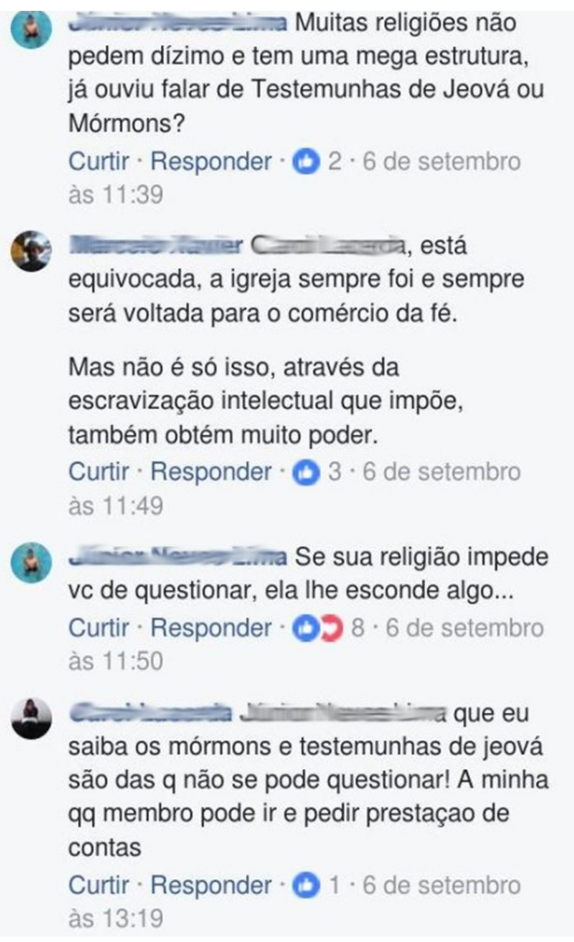

Fonte: www.facebook.com/umsabadoqualqueroficial. Publicado: 6 set.2017. Acesso: 5 out.2017

${ }^{1}$ CL é professora e pastora na Igreja Batista da Lagoinha, BH. É formada em Comunicação Institucional e Relações Públicas pelo IESB. Estudou Teologia no Seminário Teológico Carisma. Informações retiradas de sua página no Facebook. 
O comentário on-line produzido pelo sujeito $\mathrm{CL}$ caracteriza-se como enunciado concreto e reverbera em sua materialidade linguística ecos de enunciados anteriores, pertencentes ao discurso bíblico, que são perceptíveis por meio das expressões "Deus quer nosso coração" e "Deus não precisa de dinheiro", em que a prática do amor e da caridade deve ser constante na vida humana e por meio dela chegar ao reino de Deus. O sujeito CL utiliza-se da valoração oriunda dos ensinamentos bíblicos para construir sua estratégia argumentativa de convencimento, ao materializar que "a Bíblia é a palavra de Deus e o dízimo é uma prática estabelecida", fazendo uso do argumento de autoridade, que tem por objetivo "levar a plateia a aceitar um ponto de vista, baseando-se na autoridade de quem o enuncia" (FIORIN, 2017, p. 176), neste exemplo, a Bíblia.

O sujeito $\mathrm{CL}$ aponta que "Deus não precisa de dinheiro, mas a igreja tem gastos, ou uma casa de recuperação de dep. químicos não gasta? Casa para ex garotas de programas? Ex presidiários?". Utilizando-se do artifício argumentativo do exemplo, em que um princípio geral é formulado a partir da probabilidade de repetição de casos idênticos (FIORIN, 2017, p. 185), o sujeito $C L$ defende que a cobrança do dízimo pelas igrejas é legítima e o tom emotivovolitivo de seu enunciado é evidenciado pela escolha do operador argumentativo mas: "mas a igreja tem gastos", bem como pela formulação de questionamentos ao final de seu comentário, marcados linguisticamente pelo uso de interrogações.

Os comentários on-line gerados a partir da enunciação de CL configuramse como enunciados responsivos, pois todo enunciado tem antes de si outros e formulará novos enunciados (BAKHTIN, 2011), como é possível observar na primeira réplica, em que o internauta classifica como "santa e pobre" a inocência do sujeito $\mathrm{CL}$, revelando a entonação expressiva irônica, materializada a partir do uso dos adjetivos "santa" e "pobre" e valorando negativamente a crença do outro.

As réplicas dos internautas interagem diretamente com o comentário do sujeito $C L$ e buscam refutá-lo por meio do apontamento de aspectos negativos da postura de algumas igrejas, atualmente. Na segunda réplica, lemos: “[... ] mas infelizmente a igreja é como os nossos políticos [...]”, na qual a estratégia argumentativa ocorre por meio da comparação, quando "se escolhe um objeto mais conhecido e se fazem aproximações entre eles" (FIORIN, 2017, p. 122); já o uso do operador argumentativo mas reforça a 
dimensão valorativa que encontra apoio coral nos valores presumidos socialmente acerca dos representantes da política nacional.

No terceiro comentário, "o dízimo está no velho testamento, não era doado à igreja e sim a viúvas e órfãos...", a construção argumentativa por meio da valoração materializa-se no enunciado quando o sujeito-internauta recorre ao texto bíblico para contra-argumentar a exposição do sujeito $\mathrm{CL}$, esclarecendo que o dízimo tinha por objetivo a doação e não o pagamento das despesas mensais da igreja. O uso do sinal de pontuação "reticências" mostra certa resistência e ironia à postura e argumentação expostas pelo sujeito CL. Esse mesmo sujeito-internauta questiona o fato de que algumas igrejas "não pedem dízimo e tem uma mega estrutura", evidenciando o seu tom valorativo enquanto argumento por ilustração, que serve para reforçar uma tese tida como aceita (FIORIN, 2017, p. 188), tendo em vista que para CL o dízimo é necessário, já que a "igreja tem gastos".

Há ainda o reforço, por parte de um dos sujeitos-internatutas participantes do turno dialógico, de que "a igreja sempre foi e sempre será voltada para o comércio da fé." Isso transparece na escolha do advérbio de tempo sempre e em seu uso repetido, que produz um tom emotivo-volitivo de rejeição à argumentação proposta por $\mathrm{CL}$, revelando sua posição contrária àquelas colocadas pelas igrejas, tendo em vista que os valores dos enunciados são determinados de diferentes formas de relação com a realidade, com o sujeito falante e com os outros enunciados (BAKHTIN, 2016, p. 100).

Em "Se sua religião impede você de questionar, ela the esconde algo..." o sujeito-internauta parte da valoração veiculada pela dedução, raciocínio em que se vai do geral ao particular (FIORIN, 2017, p. 48), para compor a contraargumentação referindo-se ao fato de o dízimo "ser uma prática estabelecida", conforme apontou CL. Percebe-se, assim, que as palavras suprem não apenas os falantes, mas os juízos de valor mais distintos, e que, por isso, vivenciar uma experiência, formular um pensamento implica não estar indiferente; ao contrário, significa ratificá-lo de modo emotivo-volitivo (BAKHTIN, 2010).

O sujeito $C L$ procura reforço para sua defesa afirmando que as igrejas citadas "são das q não se pode questionar! A minha qualquer membro pode ir e pedir prestação de contas!". É possível observar na materialidade linguística que a argumentação reside na "relação subjetiva emocionalmente valorativa do falante com o conteúdo do objeto e do sentido de seu enunciado" 
(BAKHTIN, 2016, p. 47), refratada pela construção frasal exclamativa afirmativa, bem como pelo uso do pronome possessivo minha.

Passemos aos demais comentários:

\section{Figura 4}

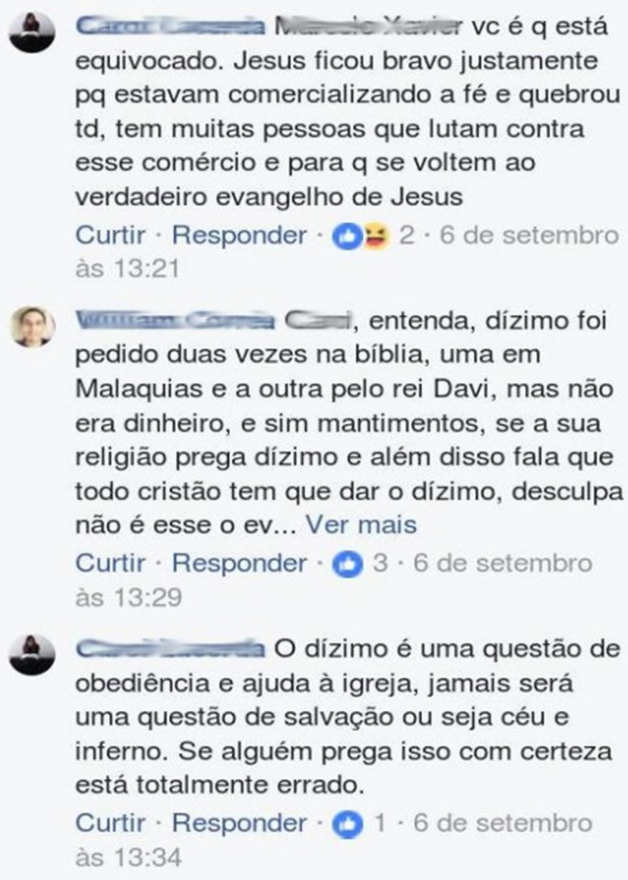

\section{Figura 5}

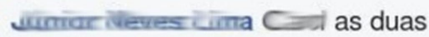

religiöes citadas por mim, são autossuficientes sem o dízimo

Curtir - Responder - $1 \cdot 6$ de setembro às $14: 00$

8)

Luizimo é questão de obediência... Isto soa como algo que uma pessoa que está sendo enganada diria.

Curtir - Responder - $2 \cdot 6$ de setembro às $14: 18$

5

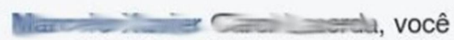
poderia explicar isso para os pastores. Acho que nenhum deles aprendeu essa parte.

Mas cuidado ao propor isso nas igrejas dos impérios do Silas Malafaia, RR Soares, Valdomiro Santiago, Edir Macedo, o clero da "santa" igreja católica e afins.

Certamente irão queimar você na fogueira santa. rs

Curtir - Responder - $1 \cdot 6$ de setembro às 16:14

Fonte: www.facebook.com/umsabadoqualqueroficial. Publicado: 6 set.2017. Acesso: 5 out.2017

$\mathrm{Na}$ continuidade do evento dialógico, o sujeito $\mathrm{CL}$ coloca-se como contrário ao comentário sobre o comércio da fé, utilizando-se do argumento do sacrifício: "aquele que busca comprovar a veracidade de uma tese pelo sacrifício de alguém que tem seja uma convicção absoluta nela ou uma grande pureza de propósito" (FIORIN, 2017, p. 164). No enunciado de CL, "Jesus" e "muitas pessoas que lutam contra esse comércio", verifica-se por meio dos elementos linguísticos "para q se voltem ao verdadeiro evangelho de Jesus" que a expressão "verdadeiro evangelho" busca revelar sua visão frente a algumas práticas de fiéis e igrejas que não se configuram como tais por não serem confiáveis ou legítimas, funcionando como elemento expressivo, isto é, como uma ponte invisível subjetiva emocionalmente valorativa do falante com o conteúdo e o sentido de seu enunciado.

Em seguida, é novamente trazido à interação o argumento por autoridade, quando um dos internautas contesta a prática do dízimo 
afirmando que ele "foi pedido duas vezes na bíblia, uma em Malaquias e outra pelo rei Davi, mas não era dinheiro e sim mantimentos", realizando a evocação da autoridade encerrada no texto bíblico, "porque ela é especialmente confiável e reconhecida como fonte de conhecimento num dado tema." (FIORIN, 2017, p. 176).

O sujeito $\mathrm{CL}$ coloca-se frente à argumentação valorando a prática do dízimo enquanto "questão de obediência à igreja" e enfatizando que "jamais será uma questão de salvação ou seja céu e inferno". Nota-se que a escolha dos elementos verbais "obediência" e "jamais" suscita certa desaprovação à prática do dízimo como um caminho de ascensão ao céu. Ratifica, ainda, que "Se alguém prega isso com certeza está totalmente errado", materialização na qual a escolha pelo elemento coesivo "se" recupera a postura de alguns líderes religiosos e veicula sua avaliação valorativa negativa frente a essa realidade, tom axiológico enfatizado pelo uso dos advérbios "com certeza" e "totalmente", pois "selecionamos aquelas palavras que, pelo tom, correspondem à expressão do nosso enunciado e rejeitamos outras." (BAKHTIN, 2016, p. 50).

Em "Dízimo é questão de obediência... isso soa como algo que uma pessoa que está sendo enganada diria", o sujeito-internauta retoma o discurso do outro e o transforma em argumento contrário, uma vez que "[...] a expressão do nosso enunciado é determinada não só - e vez por outra não tanto - pelo conteúdo semântico-objetal desse enunciado, mas também pelos enunciados do outro sobre o mesmo tema [...]." (BAKHTIN, 2011, p. 297). Por meio do jogo linguístico, instaura-se a dúvida sobre o enunciado proferido pelo sujeito $C L$ que, na visão do internauta, “está sendo enganada” pelos seus líderes religiosos.

Corroborando a ideia já veiculada de que a cobrança de dízimo por igrejas é uma prática de corrupção, é possível observar, na última réplica do bloco 4, que o sujeito-internauta sugere que o sujeito $\mathrm{CL}$ "poderia explicar isso aos pastores. Acho que nenhum deles aprendeu essa parte", enunciado esse dotado de uma valoração irônica significativa, reforçada pelo uso no pronome indefinido "nenhum" ("nenhum deles"), que coloca todos os pastores em um mesmo patamar de corrupção e extorsão. Desse modo, "o tom emotivo-volitivo envolve o conteúdo inteiro do sentido do pensamento na ação e o relaciona com o existirevento singular" (BAKHTIN, 2010, p. 87); a ironia materializada encontra apoio nos discursos sociais sobre a conduta de alguns líderes religiosos. 


\section{$\mathrm{EI} \sqcap \mathrm{dA}$}

O sujeito internauta faz, ainda, uma ressalva: "Mas cuidado ao propor isso nos impérios de Silas Malafaia, RR Soares, Valdomiro Santiago, Edir Macedo, o clero da 'santa' igreja católica e afins. Certamente irão queimar você na fogueira santa, rs.”. É possível perceber nessa construção argumentativa o uso do argumento de antimodelo que "contém características que se devem evitar" (FIORIN, 2017, p.189), de modo que os líderes protestantes citados, bem como a igreja católica, não são modelos a serem seguidos no que tange à prática da caridade. A escolha pelos adjetivos "império" e "santa" revela a intenção de mostrar a imagem social que se tem das instituições religiosas.

Por fim, as últimas réplicas:

\section{Figura 6}

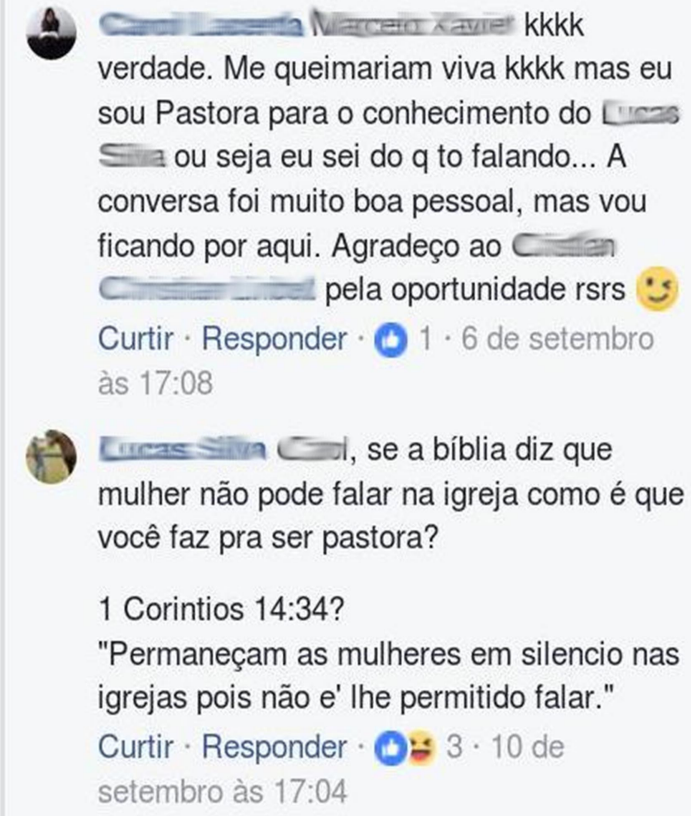

Fonte: www.facebook.com/umsabadoqualqueroficial. Publicado: 6 set.2017. Acesso: 5 out.2017

Assumindo uma postura diplomática, $\mathrm{CL}$ inicia seu enunciado marcando linguisticamente o riso e a concordância com o último comentário realizado: “kkk verdade. Me queimariam viva kkk". Em seguida, enuncia: "mas eu sou Pastora para o conhecimento do X ou seja eu sei do que estou falando...". O uso do operador argumentativo mas marca linguisticamente o posicionamento ideológico defendido por esse sujeito frente a tudo que foi exposto pelos demais internautas. Em outros termos, $\mathrm{CL}$ tem conhecimento 
de que algumas igrejas apresentam uma prática pouco idônea relativa ao dízimo e tem consciência de que são algumas igrejas e não todas.

Ao enunciar que é "Pastora", opta por grafar seu lugar de liderança religiosa com letra maiúscula, destacando-o, valorando-o perante os leitores a partir das regras da escrita, de tal forma que "cada enunciado deve ser visto antes de tudo como uma resposta aos enunciados precedentes de um determinado campo [...]." (BAKHTIN, 2011, p. 297, destaque do autor), já que os enunciados são vivos, plasmados de valoração e constituídos de traços identitários. O sujeito $\mathrm{CL}$ encerra seu turno dialógico agradecendo pela oportunidade, num tom emotivo que deixa transparecer sua experiência perante as opiniões contrárias, bem como a compreensão sobre os enunciados proferidos pelos outros que a constituíram nesse evento discursivo.

$\mathrm{Na}$ última réplica, o sujeito-internauta questiona o sujeito $\mathrm{CL}$ : "se a bíblia diz que mulher não pode falar, como é que você faz para ser pastora?”, numa última investida para que o diálogo tenha continuidade. Cabe atentar para o uso do argumento por dedução, partindo do geral para o específico (FIORIN, 2017, p. 48), realizado pelo sujeito internauta, de modo a acentuar o tom irônico realizado na pergunta, sugerindo a postura machista do sujeito-internauta, já que, segundo a Bíblia, não é possível uma mulher tornar-se pastora.

A postura do sujeito-internauta é reforçada pela alusão direta ao texto bíblico, com um trecho extraído da Epístola do Apóstolo Paulo aos cristãos de Corinto (1 Coríntios) 13:34: "Permaneçam as mulheres em silêncio nas igrejas pois não lhe é permitido falar", no qual o tom imperativo dialoga com o discurso machista cristalizado na sociedade como forma de detratar a mulher. O uso do argumento de autoridade reforça o tom emotivo-volitivo presente no enunciado, tendo em vista que o tom "expressa a verdade inteira da proposição na sua totalidade.” (BAKHTIN, 2010, p. 91), acentuando os posicionamentos axiológicos constituintes da cultura machista.

\section{Considerações finais}

As reflexões empreendidas acerca do corpus nos possibilitaram ver que o gênero comentário on-line, por materializar enunciados vivos e em constante (re)produção, mobiliza a valoração como estratégia argumentativa, utilizando-se de artifícios discursivos como a ironia, a comparação e, 
sobretudo, as diversas (re)elaborações da fala de outrem. Desse modo, sua dinâmica ratifica o postulado bakhtiniano de que o enunciado é fruto das relações dialógicas com outros enunciados e cada um está preso às suas condições sócio-históricas de produção.

Nesse contexto, a análise dos comentários on-line possibilitou a reflexão sobre a produção dos sentidos convocados pelos sujeitos-internautas e pelo uso da linguagem em contextos de interação dialógica, permitindo a compreensão, sobretudo, acerca da natureza ideológica, discursiva e argumentativa da linguagem. A análise do comentário do sujeito CL frente o enunciado materializado nos fez apreender a entonação emotivo-volitiva presente num enunciado que se propunha à defesa da igreja e da prática do dízimo, tendo em vista que "a relação valorativa do falante com o objeto (seja qual for esse objeto) também determina a escolha dos recursos lexicais, gramaticais e composicionais do enunciado." (BAKHTIN, 2011, p. 289).

Por seu turno, com as análises das réplicas, averiguamos que as formas de pensar materializadas linguisticamente pelos internautas demonstram a valoração presente em todo enunciado e que esta (a valoração) é utilizada como estratégia de defesa de um ponto de vista, seja na forma de argumento de autoridade, de ironia, de exemplificação, entre outros, conforme vimos em Fiorin (2014). Essas estratégias denotam tons emotivo-volitivos e entonações expressivas que retomam discursos anteriores, proferidos em outros tempos e lugares, caracterizando o devir existente na linguagem.

Destacamos que tais leituras rumam para o entendimento de que o campo discursivo da religião é um terreno fértil de entonações, vozes e tramas discursivas, figurando socialmente ora como acolhedor, ora como impositivo, ora como permissivo.

\section{Referências}

ARAÚJO, Patrícia Silva Rosas de. Análise dialógica de réplicas no gênero comentário on-line: a compreensão responsiva ativa sobre o segundo casamento cristão-católico. João Pessoa, 2017. 161f. Tese (Doutorado) - Programa de Pós-Graduação em Linguística da Universidade Federal da Paraíba, 2017.

BAKHTIN, Mikhail Mikhailovich. Para uma filosofia do ato responsável. Tradução: Valdemir Miotello e Carlos Alberto Faraco. São Carlos: Pedro e João Editores, 2010. 
Fontes, 2011.

. Estética da criação verbal. Tradução: Paulo Bezerra. 5. ed. São Paulo: Martins

. Os gêneros do discurso. Tradução, posfácio, notas e glossário: Paulo Bezerra. Notas da edição russa: Serguei Botcharov. São Paulo: 34, 2016.

FARACO, Carlos Alberto. Linguagem e diálogo: as ideias linguísticas do círculo de Bakhtin. São Paulo: Parábola Editorial, 2009.

FIORIN, José Luiz. Argumentação e discurso. Bakhtiniana, São Paulo, v. 9, n. 1, p. 5370, jan./jul. 2014.

. Argumentação. 1. ed., 3. reimpr. São Paulo: Contexto, 2017.

KOZINETS, Robert. Netnografia: realizando pesquisa etnográfica online. Porto Alegre: Penso, 2014.

MELO, José Marques de. Jornalismo opinativo: gêneros opinativos no jornalismo brasileiro. 3. ed. São Paulo: Mantiqueira, 2003.

PISTORI, Maria Helena Cruz; BANKS-LEITE, Luci. Argumentação e construção de conhecimento: uma abordagem bakhtiniana. Bakhtiniana, São Paulo, v. 1, n. 4, p. 129144, 2010.

. Dialogia na persuasão "publicitária”. Bakhtiniana, São Paulo, v. 1, n. 9, p. 148167, jan./jul. 2014.

PUZZO, Miriam Bauab. As imagens de Lula na revista Veja sob perspectiva dialógica da linguagem. In: BRAIT, Beth; MAGALHÃES, Anderson (org.). Dialogismo: teoria e(m) prática. São Paulo: Terracota, 2014. p.171-194.

VOLOCHÍNOV, Valentin. Marxismo e filosofia da linguagem: problemas fundamentais do método sociológico na ciência da linguagem. Tradução, notas e glossário: Sheila Grillo e Ekaterina Vólkova Américo. São Paulo: 34, 2017.

\section{Forma de citação sugerida}

MEDEIROS E OLIVEIRA, Alixandra Guedes Rodrigues de; FRANCELINO, Pedro Farias. O tom valorativo como estratégia argumentativa no gênero comentário on-line. EID\&A - Revista Eletrônica de Estudos Integrados em Discurso e Argumentação, Ilhéus, n. 17, p. 2-18, jul./dez.2018. DOI dx.doi.org/10.17648/eidea-17-1943. 